\title{
RESEARCH OF SENSOMOTOR REACTION, MEMORY AND ATTENTION INDICIES UNDER SENSORY DEPRIVATION
}

\author{
Yulia Zagaykan ${ }^{1}$ \\ Julyashechka@i.ua \\ Oleksandr Spryn ${ }^{l}$ \\ aleksandrsprun@gmail.com \\ Nikolay Zagaykan \\ Kherson Children's Regional Clinical Hospita ${ }^{1}$ \\ 81 Ukraiinska str., Kherson Ukraine 73013 \\ Zagaykan7@i.ua \\ ${ }^{1}$ Department of Human Biology and Immunology \\ Kherson State University \\ 27 Universytetska str., Kherson, Ukraine, 73000
}

\begin{abstract}
The article considers the influence of sensory (visual and auditory) deprivation on a sensorimotor response, memory, and attention among 8-11 years old children. The literature review concludes that sensory deprivation causes discomfort and problems in perceiving of reality. Also, under the influence of various factors that damage body structures, compensatory reactions are launched to compensate for impaired functions. The processes that provide the body with the restoration of lost structures and impaired functions of the pathology are called «compensatory-adaptive processes». Having conducted statistical analysis of the obtained data of latent periods of different sensomotor responses among children with sensory deprivation and the control group, it is seen, that the level of stimuli in the form of figures was higher among children with hearing impairments, and in the form of sounds - in the group of children with visual impairments. According to the results of our study, we can assume that in groups of children with sensory deprivation the process of compensating the impaired function of a particular analyzer takes place at the expense of another one.
\end{abstract}

Keywords: sensomotor response, latency period, sensory deprivation, compensatory reactions, memory, attention.

DOI: $10.21303 / 2504-5695.2019 .00977$

\section{Introduction}

In Ukraine, the health of children and young people cannot be considered satisfactory. Among the negative factors, affecting the health of preschool and school-age children, are hearing and visual impairment, infections, traumas, and overuse of modern electronic devices.

Nowadays, children with hearing and visual impairments take a significant place among children with disturbances of development. According to the world statistics, in progressive countries, every twentieth preschool child and every fourth schoolchild has visual impairments. The most common childhood diseases are myopia, hyperopia, and astigmatism. As for hearing, according to the statistics, in Ukraine, there are more half a million children with hearing impairments. More than $6 \%$ of the population has severe hearing impairments, so the problem of deafness and hearing loss is as important as vision problems [1].

The phenomenon of sensory deprivation attracted the interest of people for a long time. In some scientific works the arrest of a child's response is explained as a result of the deprivation of contact with the outside world and the environment. Some works indicate that children's long-term sensory deprivation causes disturbance of the mechanisms of the analytical system of the brain, leads to deviations in the development of its activating and regulating systems and their interaction. Also, the limited receipt of sensory information leads to the formation of emotional stress (Solntseva L., 2000) and creates unusual conditions for the development of the child's psyche $[2,3]$. 
At the end of the twentieth century, active research began concerning a sensory deprivation's influence on the child's psychophysiological development. Most data do not give a complete picture of the effect of deprivation on the overall functional state, so our study aims to obtain and analyze scientific data on the specificity of the effects of visual and auditory deprivation on sensomotor response, memory, and attention [4-6].

\section{Materials and Method}

\section{1. Organization of the research}

The study was conducted in compliance with the basic biotic provisions of the Council of Europe Convention on Human Rights and Biomedicine (04.04.1997), the World Health Association's Helsinki Declaration on Ethical Principles for Conducting Scientific Medical Research with Human Participation (1964-2008), and the Order Ministry of Health of Ukraine No. 690 dated September 23, 2009.

We have officially formalized contracts with schools No. 01-27/1918 dated September 21, 2015; 05-13/53 dated October 01, 2015 and No. 01-27/2237 dated November 04, 2015. We have obtained the informational consent from the parents/guardians of patients.

The survey involved 155 individuals aged $8-11$ years. The students were divided into 3 groups: the $1^{\text {st }}$ group - control (children with normal vision and hearing); the $2^{\text {nd }}-$ schoolchildren with visual deprivation; the $3^{\text {rd }}$ group - students with auditory deprivation. Each group, in turn, was divided into two subgroups by age: $1^{\text {st }}$ subgroup included students aged $8-9$ years; $2^{\text {nd }}$ subgroup 10-11 years ones.

A group of students with visual sensory deprivation consisted of children, who had refractive abnormalities: inborn myopia, astigmatism, myopia. Based on of studying medical records, 51 students were selected (26-8-9 years old, and 25 individuals aged 10 to 11 years).

The group of students with auditory sensory deprivation consisted of children, who had inborn or early acquired pairedsensoneural hearing loss of II-III degrees. Based on the analysis of medical records and audiogram data, 53 students were selected (8-9 years - 26; 10-11 years - 27). Children with traumatic brain injury and asymmetric hearing were not included in the examination.

The control group consisted of 51 persons (8-9 years -25 ; 10-11 years -26$)$, who have no visual or hearing impairment.

The study took place during 2016-2018, based on the Kherson boarding schools of the Kherson regional council, Kherson educational complex No. 11, and No. 48, as well as at the comprehensive school№31 in Kherson.

Taking into account fluctuations in mental capacity during the working day and week, all studies were conducted on days of high mental capacity: on Tuesday - Thursday from 9.00 till $13.00[7,8]$. The total amount of experimental study for each observable was no more than 30-40 minutes per examination.

The order of the research for the whole contingent of the subjects was carried out according to the same scheme and was as follows: first, the sensorimotor response to stimuli of different complexity was studied (figures and sounds), which was developed on the device. The reliability of this technique was proved by the data of a number of experimental works, performed on adults and children [9-11]. Subsequently, a set of techniques for determining memory and attention functions was used.

\section{2. Methods of research of sensomotor response}

In the study of visual/auditory motor reactions of different degrees of difficulty a computer system «Diagnost-1M» was used, which was created in the laboratory of physiology of a human's higher nervous activity at the Bohomolets Institute of Physiology (Ukraine).This technique allows to evaluate individual speed features of a person, to identify their ability to perform effectively and adequately under the conditions of processing information of varying degrees of complexity [12].

The studies started with the determination of the latent period of the simple visual/auditory motor response (LP SVAMR). The task was to react as quickly as possible by pressing and releas- 
ing the button with the right hand, when a stimulus - any geometric figure (sounds of different tones) appeared on the screen. The observable was given 30 signals. Exposure time was $0.9 \mathrm{sec}$, and the pause duration was changed randomly, which was included in the program and did not depend on the response rate of the subject. After the presentation of stimuli, average time latency in milliseconds of SVAMR $\left(M_{a v}\right)$, standard deviation $(\sigma)$, coefficient of variation $(\mathrm{CV})$, and error of arithmetic mean value $(\mathrm{m} \pm)$ appeared on the screen.

After determination of SVAMR, a latent reaction period of one of three stimuli choice (LRPSC 1-3) was detected. The examined were presented with the same signals in the same amount as under the terms of the SVAMR determination, but taking into account their differentiation. The examined had to press and release the right button with the right hand as soon as possible, when the «square» appeared on the screen (high-pitched sound) and take no action, when a «triangle» or «circle» (low- and mid-tone) appears. Signal exposure was also $0.9 \mathrm{~s}$.

The determination of the latency period of two of three stimuli choice (LRPSC 2-3) differed from the previous test in that the subject was offered, except for the right-hand response to the figure «Square» (high pitched sound) to respond as soon as possible to the appearance of a figure «Circle» (low tone) by clicking the left button with the left hand. If a triangle appears on the screen (middle tone), the examined had to press no button, as it was a brake. The tempo, duration of exposure, and pause between stimuli were the same as in the previous study.

\section{3. Methods of memory and attention research}

Various types of material (geometric shapes, numbers, and words) were suggested for the study of short-term visual memory of schoolchildren, presented in the form of tables of 10 depicted elements.

30 seconds were given to memorize cards with geometric shapes, numbers, and words. The examined had 30 seconds to retain the material he/she had to memorize. Then, within 1 minute, the student had to randomly reproduce what he/she had seen in writing. We had calculated the number of correctly reproduced material.

The performance (volume) index of short-term visual memory depended on the number of correctly reproduced elements of each table (the bigger the number of elements, the higher the memory capacity).

We used correction tables by Anfimov and «red and black» Schulte tables to study attention.

The corrective method allows to obtain data on the mental capacity of the child, the level of mental capacity (the speed of the fulfilling the task and its accuracy), to study the speed and the nature of the conditioned reflex. Proofreading tables were used in the study of performance, speed, and volume of attention. Anfimov's tables are presented in the form of printed 1600 characters in the form of 40 lines (40 characters in each row). These characters are represented by eight letters of the Russian alphabet: A, В, E, И, К, Н, С, X in a chaotic order. The subject should, in the allotted time (4 minutes), cross out as many specific letters as possible.

To evaluate the completed task, it is necessary to take into account the total number of characters processed (attention span), the number of crossed out characters, mistakes made, omitted characters. formulas:

Volume, speed, stability, performance, and accuracy of attention were calculated by the

- volume of attention (Q):

$$
Q=N / 1600 \text {, }
$$

where $N$ is the number of characters, processed in 4 minutes; 1600 is the total number of characters. - speed of the processed information $(\mathrm{H})$ : 
where $N$ is the number of characters, processed in 4 minutes; $t$ - time of the task.

- indicators of stability $(A)$ and performance $(E)$ of attention were calculated by the Whipple formulas:

$$
A=\frac{C-O}{C+M}
$$

where $C$ is the number of crossed out characters; $O$-the number of omitted characters that should have been crossed out;

$\mathrm{M}$ is the number of made mistakes.

$$
E=A \cdot N,
$$

where $A$ is an indicator of the stability of attention; $N$-the number of characters, processed in 4 minutes.

- attention accuracy (S):

$$
S=C / n \cdot 100 \%,
$$

where $C$ is the number of crossed out characters; $n$ is the number of characters to be crossed out.

The «red and black» Schulte table technique is intended to evaluate the switching of attention. The examined were offered a table, divided into 49 cells $(7 \times 7)$ with red and black numbers. They need to find red and black numbers in turn, with reds in the descending order (from 24 to 1) and blacks in the increasing order (from 1 to 24). Only the letters that are near the numbers are needed to be written wind. Working time -5 minutes. The faster the subject performed the task, the higher the level of shifting attention.

\section{4. Statistical Analysis}

Statistical processing of the obtained experimental material was performed by parametric and non-parametric statistics using Microsoft Excel and Statistica for Windows 6.0. The reliability of changes and differences between the studied values was evaluated by the criterion of difference $(t)$ according to the Student's table, the nonparametric criterion «U» Wilcoxon-Mann-Whitney [13].

\section{Results}

Having conducted the statistical analysis of the obtained data of latent periods of different sensomotor responses among children with sensory deprivation and the control group, it is seen, that the level of stimuli in the form of figures was higher among children with hearing impairments, and in the form of sounds - in the group of children with visual impairments. This was observed in both age subgroups [14].

It has been revealed that the latent period of simple visual-motor reactions of children with auditory sensory deprivation to figure statistically almost does not differ from similar indicators of the control group children. This is observed in both age subgroups. Thus, in the group of children with auditory sensory deprivation at the age of 8-9 years, the average group indicator of SVAMR is $347.3 \pm 5.5 \mathrm{msec}$, and in the control group, the comparatively shorter latency periods are $331.2 \pm 5.7 \mathrm{msec}$. The indicator of the group of children with visual deprivation was longer and totaled $457.6 \pm 6.2 \mathrm{~ms}$.

In the group of children with auditory sensory deprivation at the age of 10-11 years, the average group index of SVAMR is $271.7 \pm 4.9 \mathrm{msec}$, and the control group has comparatively longer latency periods $-284.5 \pm 5.7 \mathrm{msec}$. The indicator of the group of children with visual deprivation was $363.7 \pm 6.6$ msec longer (Table 1, Fig. 1). 
Table 1

Average indicators of sensorimotor reactions among children to figures

\begin{tabular}{ccccccc}
\hline \multirow{2}{*}{ Index } & \multicolumn{2}{c}{ Control group } & $\begin{array}{c}\text { Group of children with visual } \\
\text { deprivation }\end{array}$ & $\begin{array}{c}\text { Group of children with hearing } \\
\text { deprivation }\end{array}$ \\
\cline { 2 - 7 } & $\begin{array}{c}\mathbf{8 - 9} \text { years } \\
(\mathbf{n = 2 5})\end{array}$ & $\begin{array}{c}\mathbf{1 0 - 1 1} \text { years } \\
(\mathbf{n}=\mathbf{2 6})\end{array}$ & $\begin{array}{c}\mathbf{8 - 9} \text { years } \\
(\mathbf{n = 2 6})\end{array}$ & $\begin{array}{c}\mathbf{1 0}-\mathbf{1 1} \text { years } \\
(\mathbf{n}=\mathbf{2 5})\end{array}$ & $\begin{array}{c}\mathbf{8 - 9} \text { years } \\
(\mathbf{n}=\mathbf{2 6})\end{array}$ & $\begin{array}{c}\mathbf{1 0}-\mathbf{1 1} \text { years } \\
(\mathbf{n}=\mathbf{2 7})\end{array}$ \\
\hline LP SVAMR & $331.2 \pm 5.7$ & $284.5 \pm 5.6$ & $457.6 \pm 6.2^{* *}$ & $363.7 \pm 6.6^{* *}$ & $347.3 \pm 5.5$ & $271.7 \pm 4.9$ \\
LRPSC 1-3 & $505.3 \pm 7.3$ & $443.3 \pm 7.8$ & $546.2 \pm 7.2^{*}$ & $481.5 \pm 5.9^{*}$ & $475.8 \pm 7.9^{*}$ & $407.5 \pm 6.3^{*}$ \\
LRPSC 2-3 & $603.1 \pm 6.5$ & $528.2 \pm 7.4$ & $624.3 \pm 5.7^{*}$ & $576.7 \pm 5.1^{*}$ & $578.2 \pm 6.5^{*}$ & $479.4 \pm 7.5^{*}$
\end{tabular}

Note: LPSVAMR (msec) is the latent period of simple visual-motor reactions; LRPSC 1-3 (msec) is the latent reaction period for selecting one of three stimuli; LRPSC 2-3 (msec) is the latent reaction period of choice of 2-3 stimuli. The probability of difference between groups $*-p<0.05 ; * *-p<0.01-$ the difference is significant with respect to the children of the control group.

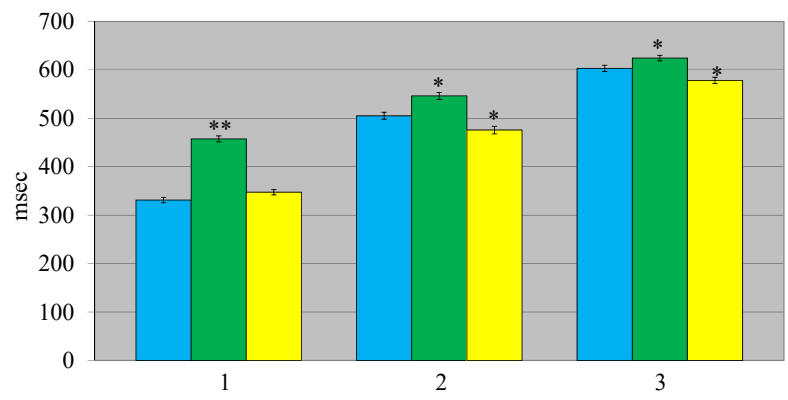

Fig. 1. Indicators of the latent periods of different visual and motor reactions among children of 8-9 years of age on the figures: 1 - LPSVAMR; 2 - LRPSC1-3; 3 - LRPSC 2-3;

- Control group; _ - Group with visual impairments; - Group with hearing impairments

Mean values of LRPSC 1-3 among children with auditory sensory deprivation were better and was equal in the subgroup $8-9$ years $-475.8 \pm 7.9 \mathrm{~ms}(10-11$ years $-407.5 \pm 6.3)$, for children of the control group $-505.3 \pm 7.2 \mathrm{~ms}(10-11$ years $-443.3 \pm 7.8)$, and in the group of children with visual impairments $-546.2 \pm 7.2$ mess (10-11 years $-481.5 \pm 5.9 \mathrm{~ms})$. When analyzing - LRPSC 1-3 indicators, using Student's test, we found significant differences in the survey groups (Table 1, Fig. 1; 2).

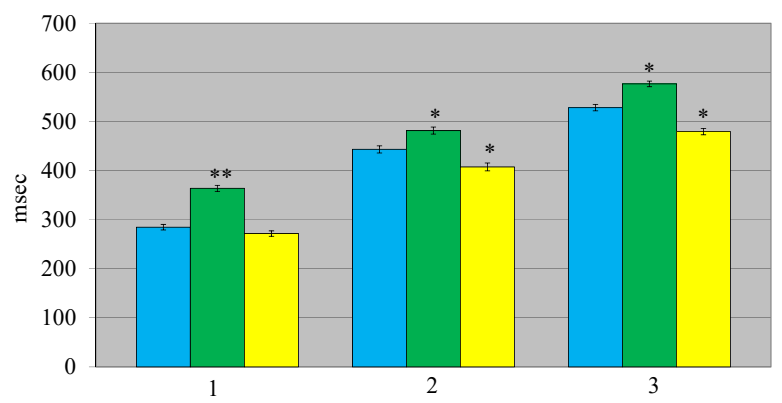

Fig. 2. Indicators of the latent periods of different visual and motor reactions among children of 10-11 years of age on the figures: 1 - LPSVAMR; 2 - LRPSC 1-3; 3 - LRPSC 2-3;

- Control group; _ - Group with visual impairments; - Group with hearing impairments

The mean values of LRPSC 2-3 among children with visual sensory deprivation were longer $(p<0.001)$ and were equal to $624.3 \pm 5.7 \mathrm{~ms}(10-11$ years $-576.7 \pm 5.1 \mathrm{~ms})$, for children in the control group of 8-9 years - 603.1 $\pm 6.5(10-11$ years $-528.2 \pm 7.4) \mathrm{ms}$, and in students with hearing impairments the average group indicator was the best $-578.2 \pm 6.5 \mathrm{~ms}(10-11$ years $-479.4 \pm 7.5 \mathrm{~ms})$.

We conducted and obtained the results of the study of sensomotor reactions among children with sensory deprivation and the control group for sound stimuli ( 3 sounds with a different tone: low, middle and high tone). The results are presented in Table 2. 
After conducting a statistical analysis of the obtained data of the latent periods of different sensomotor responses in the experimental and control groups, the level was higher in the group of pupils with visual deprivation (Table 2, Fig. 3, 4).

The latent periods of simple auditory motor responses among children with visual impairments to sounds were found to be statistically better than those of children in the control group and the group of students with hearing impairments. Thus, in the group of children with visual sensory deprivation mean LP SVAMR value in the subgroup aged 8-9 years is $351.1 \pm 5.3 \mathrm{~ms}$ (10-11 years $-346.7 \pm 6.3 \mathrm{~ms})$, the control group had slightly longer latency periods $-366.8 \pm 5.3 \mathrm{~ms}$ (10-11 years $-352.1 \pm 6.1 \mathrm{~ms})$. In the group of schoolchildren of 8-9 years with hearing impairment, the LP SVAMR was worse and was $536.2 \pm 6.3 \mathrm{~ms}$ (10-11 years $-511.7 \pm 5.1)$. This is explained by the existing hearing aid problems among children with hearing impairments and the high level of spatial hearing development in people with visual impairments.

Table 2

Average indicators of sensorimotor reactions among children to sounds

\begin{tabular}{|c|c|c|c|c|c|c|}
\hline \multirow{2}{*}{ Indicator } & \multicolumn{2}{|c|}{ Control group } & \multicolumn{2}{|c|}{$\begin{array}{c}\text { Group of children with visual } \\
\text { impairments }\end{array}$} & \multicolumn{2}{|c|}{$\begin{array}{c}\text { Group of children with hearing } \\
\text { impairment }\end{array}$} \\
\hline & $\begin{array}{c}8-9 \text { years } \\
(n=25)\end{array}$ & $\begin{array}{c}10-11 \text { years } \\
(n=26)\end{array}$ & $\begin{array}{c}8-9 \text { years } \\
(n=26)\end{array}$ & $\begin{array}{c}10-11 \text { years } \\
(n=25)\end{array}$ & $\begin{array}{c}\text { 8-9 years } \\
(\mathrm{n}=26)\end{array}$ & $\begin{array}{c}10-11 \text { years } \\
(n=27)\end{array}$ \\
\hline LP SVAMR & $366.8 \pm 5.3$ & $352.1 \pm 6.1$ & $351.1 \pm 5.3$ & $346.7 \pm 6.3$ & $536.2 \pm 6.3^{* * *}$ & $511.7 \pm 5.1 * * *$ \\
\hline LRPSC 1-3 & $415.7 \pm 7.6$ & $381.2 \pm 5.8$ & $409.5 \pm 6.2$ & $375.3 \pm 6.9$ & $593.4 \pm 7.2 * * *$ & $579.3 \pm 5.6^{* * *}$ \\
\hline LRPSC 2-3 & $498.5 \pm 5.8$ & $479.3 \pm 6.4$ & $480.1 \pm 5.5^{*}$ & $461.8 \pm 6.1^{*}$ & $596.2 \pm 5.5^{* *}$ & $566.1 \pm 7.2^{* *}$ \\
\hline
\end{tabular}

Note: LP SVAMR (msec) is the latent period of simple visual-motor reactions; LRPSC 1-3 (msec) is the latent reaction period for selecting one of three stimuli; LRPSC 2-3 (msec) is the latent reaction period of choice of 2-3 stimuli. The probability of difference between groups ${ }^{*}-p<0.05 ; *{ }_{-}-p<0.01 ; * * *-p<0,001$ - the difference is significant with respect to the children of the control group

The mean values of CRT 1-3 among children with auditory sensory deprivation at the age of $8-9$ years were longer $(\mathrm{p}<0.001)$ and equaled $593.4 \pm 7.2 \mathrm{~ms}(10-11$ years $-579.3 \pm 5.6 \mathrm{~ms})$, for control children $-415.7 \pm 7.6 \mathrm{~ms}(10-11$ years $-381.2 \pm 5,8)$, and in the group with visual impairments $-409.5 \pm 6.2 \mathrm{~ms}(10-11$ years $-375.3 \pm 6.9)$. The very large difference between healthy and impaired students can be explained by the fact that children with hearing problems respond better to low-key stimuli than high-key stimuli. When analyzing LRPSC 1-3 indicators, using Student's t-test, we found significant differences in the survey groups (Table 2, Fig. 3, 4).

The mean values of LRPSC 2-3 among children 8-9 years with auditory sensory deprivation were longer $(\mathrm{p}<0.001)$ and equaled $596.2 \pm 5.5 \mathrm{~ms}(566.1 \pm 7.2 \mathrm{~ms})$, for control children $498.5 \pm 5.8 \mathrm{~ms}(10-11$ years $-479.3 \pm 6.4)$. The best results were recorded in students with visual problems $-480.1 \pm 5.5(10-11$ years $-461.8 \pm 6.1) \mathrm{ms}$. This is because the visually impaired have better developed auditory memory, they are quicker to understand and determine the source of the sound.

Therefore, the best performance of sensorimotor functions for sounds is in the visually impaired children as opposed to healthy and visually impaired. This is explained by the present hearing problems among children with hearing impairments and high levels of spatial hearing development in people with impaired vision due to the need to navigate in a diverse sound field. Significant differences are observed between the indicators of LRPSC 1-3 and LRPSC 2-3 in sensory-deprived children with hearing impairment as opposed to healthy ones. This means that hearing impaired students are more likely to perceive low-pitched sounds than high-pitched ones.

In addition to neurodynamic and sensorimotor functions, we also studied the memory and attention features of children with visual and hearing impairments.

When conducting a study on the amount of short-term visual memory, significant differences were found in the indicators of short-term visual mechanical memory between children with sensory deprivation, and the control group. 


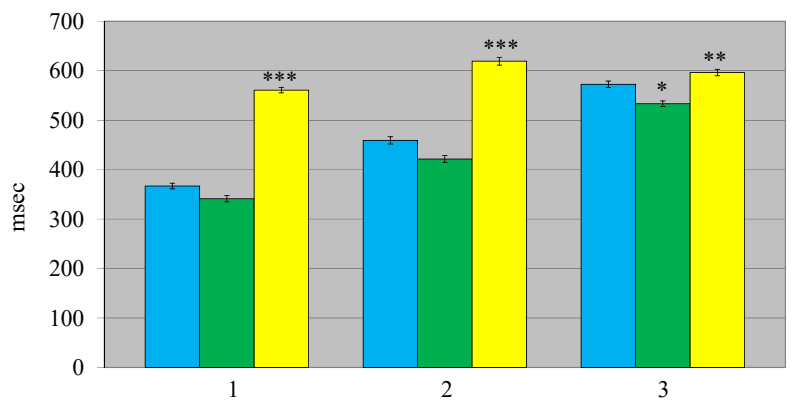

Fig. 3. Indicators of the latent periods of auditory-motor reactions of different complexity among children of 8-9 years for sounds: 1 - LPSVAMR; 2 - LRPSC 1-3; 3 - LRPSC 2-3;

- Control group; _ - Group with visual impairments; _ - Group with hearing impairments

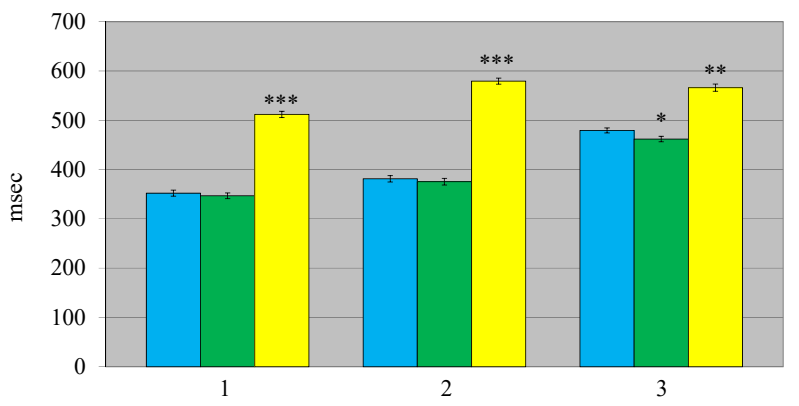

Fig. 4. Indicators of the latent periods of auditory-motor reactions of different complexity among children of 10-11 years for sounds: 1 - LPSVAMR; 2 - LRPSC 1-3; 3 - LRPSC 2-3;

- Control group; - Group with visual impairments; - Group with hearing impairments

Students in the control group, in contrast to sensory-deprived children, have higher memory scores for numbers and one-/two-syllables words. So, in the control group of children aged 8-9 years the index of number memorizing reached $6.35 \pm 0.18$ points (10-11 years $6.56 \pm 0.19)$, among children with hearing impairments $-5.62 \pm 0.18(10-11$ years $-5.83 \pm 0.12)$, and in the group with visual impairments $-4.69 \pm 0.14$ points $(4.87 \pm 0.21)$. The indicator for one- and two-syllables words in healthy students of $8-9$ years $-5.41 \pm 0.21$ points $(10-11$ years $-5.66 \pm 0.22)$, group with visualdeprivation $4.15 \pm 0.17$ (4.29 \pm 0.11 ), and auditory $-5.18 \pm 0.13$ (5.47 \pm 0.16 ) (Table 3, Fig. 5, 6).

When comparing the short-term memory on geometric figures, it was founded that in students with hearing deprivation of both age subgroups indices are higher in contrast to the control group. In the group with visual impairment of $8-9$ years, it is $6.65 \pm 0.15$ points, and in students of 10-11 years $-6.81 \pm 0.20$ (Table 3). A better indicator of imaginative memory (remembering figures) can be explained by the different way of formation of the second system (an image - a gesture).

Table 3

Average rates of memorization of different material among children 8-11 years

\begin{tabular}{ccccccc}
\hline \multirow{2}{*}{$\begin{array}{c}\text { Memory vol- } \\
\text { ume, points }\end{array}$} & \multicolumn{2}{c}{ Control group } & \multicolumn{2}{c}{$\begin{array}{c}\text { Group of children with visual } \\
\text { impairments }\end{array}$} & \multicolumn{2}{c}{$\begin{array}{c}\text { Group of hearing impaired } \\
\text { children }\end{array}$} \\
\cline { 2 - 7 } & $\begin{array}{c}\mathbf{8 - 9} \text { years } \\
(\mathbf{n = 2 5})\end{array}$ & $\begin{array}{c}\mathbf{1 0 - 1 1} \text { years } \\
(\mathbf{n}=\mathbf{2 6})\end{array}$ & $\begin{array}{c}\mathbf{8 - 9} \text { years } \\
(\mathbf{n = 2 6})\end{array}$ & $\begin{array}{c}\mathbf{1 0}-\mathbf{1 1} \text { years } \\
(\mathbf{n}=\mathbf{2 5})\end{array}$ & $\begin{array}{c}\mathbf{8}-\mathbf{9} \text { years } \\
(\mathbf{n}=\mathbf{2 6})\end{array}$ & $\begin{array}{c}\mathbf{1 0 - 1 1} \text { years } \\
(\mathbf{n}=\mathbf{2 7})\end{array}$ \\
\hline geometricshapes & $6.51 \pm 0.13$ & $6.76 \pm 0.15$ & $4.97 \pm 0.12^{* *}$ & $5.09 \pm 0.18^{* *}$ & $6.65 \pm 0.15$ & $6.81 \pm 0.20$ \\
numbers & $6.35 \pm 0.18$ & $6.56 \pm 0.19$ & $4.69 \pm 0.14^{* *}$ & $4.87 \pm 0.21^{* *}$ & $5.62 \pm 0.18^{*}$ & $5.83 \pm 0.12^{*}$ \\
words & $5.41 \pm 0.21$ & $5.66 \pm 0.22$ & $4.15 \pm 0.17^{* *}$ & $4.29 \pm 0.11^{* *}$ & $5.18 \pm 0.13$ & $5.47 \pm 0.16$
\end{tabular}

Note: $*-p<0.05 ; * *-p<0.01-$ the difference is significant with respect to the children of the control group

The results of the study revealed that children with visual deprivation of 8-11 years are worse in remembering the material, unlike the control group and students with auditory depri- 
vation. This indicates that visually impaired students' memory is related to the visual analyzer, developed at a low level. For problems with eyesight impose its imprint on our received findings.

Also, the presented results give grounds to claim that the older the child, the higher the rates of short-term visual memory.

Attention is a dynamic characteristic of activity, as it activates the necessary and inhibits unnecessary mental processes, promotes a purposeful selection of received information, regulates and controls the course of activity. Attention is characterized by such features as volume, selectivity, stability, distribution, switching. All these properties are formed among children gradually in preschool and younger school age $[16,17]$.

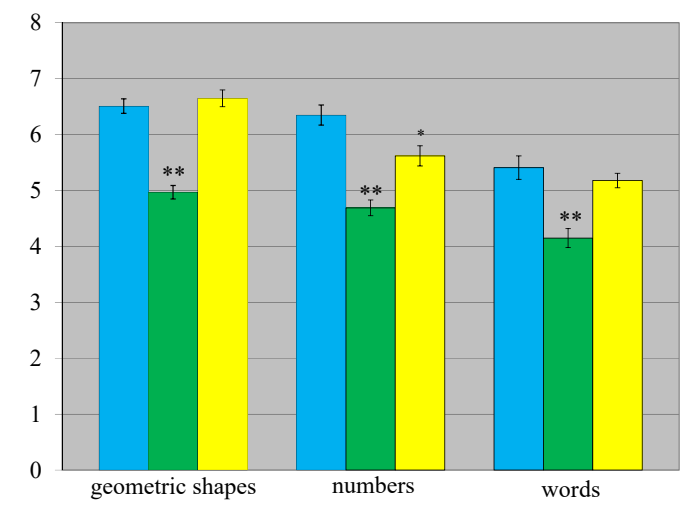

Fig. 5. Indicators of short-term visual memory among the children $8-9$ years:

- Control group; _ - Group with visual impairments; _ - Group with hearing impairments

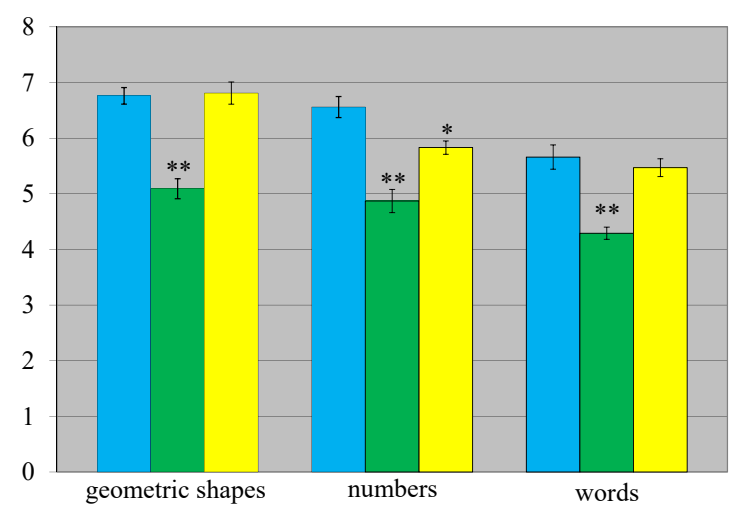

Fig. 6. Indicators of short-term visual memory among children 10-11 years:

- Control group; - Group with visual impairments; - Group with hearing impairments

Table 4

Mean values of attention features of students of $8-11$ years

\begin{tabular}{ccccccc}
\hline \multirow{2}{*}{ Indexes } & \multicolumn{2}{c}{ Control group } & \multicolumn{2}{c}{$\begin{array}{c}\text { Group of children with visual } \\
\text { impairments }\end{array}$} & \multicolumn{2}{c}{$\begin{array}{c}\text { Group of hearing impaired } \\
\text { children }\end{array}$} \\
\cline { 2 - 7 } & $\begin{array}{c}\mathbf{8 - 9} \text { years } \\
(\mathbf{n = 2 5})\end{array}$ & $\begin{array}{c}\mathbf{1 0 - 1 1} \text { years } \\
(\mathbf{n = 2 6})\end{array}$ & $\begin{array}{c}\mathbf{8 - 9} \text { years } \\
(\mathbf{n = 2 6})\end{array}$ & $\begin{array}{c}\mathbf{1 0}-\mathbf{1 1} \text { years } \\
(\mathbf{n}=\mathbf{2 5})\end{array}$ & $\begin{array}{c}\mathbf{8}-\mathbf{9} \text { years } \\
\mathbf{( n = 2 6 )}\end{array}$ & $\begin{array}{c}\mathbf{1 0}-\mathbf{1 1} \text { years } \\
(\mathbf{n}=\mathbf{2 7})\end{array}$ \\
\hline Volume & $618 \pm 17.2$ & $621 \pm 19.3$ & $619 \pm 15.4$ & $623 \pm 18.3$ & $622 \pm 15.7$ & $628 \pm 16.1$ \\
Productivity & $532 \pm 18.7$ & $541 \pm 16.8$ & $472 \pm 14.6^{*}$ & $488 \pm 15.3^{*}$ & $478 \pm 14.5^{*}$ & $491 \pm 15.6^{*}$ \\
Stability & $0.91 \pm 0.01$ & $0,93 \pm 0,01$ & $0.85 \pm 0.01^{*}$ & $0.87 \pm 0.01^{*}$ & $0.85 \pm 0.01^{*}$ & $0.86 \pm 0.01^{*}$ \\
Switching & $294 \pm 8.5$ & $291 \pm 8.4$ & $324 \pm 10.7^{* *}$ & $320.5 \pm 7.6^{* *}$ & $320 \pm 9.7^{* *}$ & $318 \pm 10.9^{*}$ \\
Speed & $5.4 \pm 0.12$ & $5.7 \pm 0.15$ & $4.9 \pm 0.16^{*}$ & $5.1 \pm 0.11^{*}$ & $4.8 \pm 0.12^{*}$ & $5.1 \pm 0.18^{*}$
\end{tabular}

Note: ${ }^{*}-p<0.05 ;^{* *}-p<0.01-$ the difference is significant with respect to the children of the control group 
Significant differences between the indicators are observed between sensory deprivation students and controls when conducting the survey and obtaining the results of attention traits.

A detailed analysis of the results of the study showed that the volume of attention among children with visual and hearing impairments was significantly higher than in the control group. Thus, in the group of schoolchildren with visual deprivation of 8-9 years, the volume of attention was $619 \pm 15.4(10-11$ years $-623 \pm 18.3)$, with auditory deprivation $-622 \pm 15.7(628 \pm 16.1)$ and $618 \pm 17.2$ $(621 \pm 19.3)$ in the control group.

Analyzing the data in Table 4, we can observe the low speed of information processing in sensory-deprived children of 8-11 years. The focus is on increased perceptual loading, which requires deeper focus and resilience. Due to the high tension, children are more tired. This leads to a slower pace of tasks and an increase in the number of errors. It can be assumed, that this is due to abnormalities of the central nervous system that can cause deprivation.

Performance, resilience, and shifting performance are better in the children from the control group as opposed to students with visual and hearing impairments. Schoolchildren with visual and hearing impairments have difficulty switching attention, they need more time, which leads to a decrease in the speed of the task fulfilling and increase the number of mistakes.

Analyzing literary sources, we can assume that virtually all qualities of attention, such as activity, focus, latitude (volume, distribution), switching ability, intensity, or concentration, resilience are affected by visual impairment, but children with visual impairments, who are capable of high development, reach, and sometimes exceed the level of development of these qualities in people, who don't have sight deprivation.

\section{Conclusions}

The study of sensorimotor response to the burden of varying degrees of complexity revealed that:

- latent periods of simple visual-motor responses among children with auditory sensory deprivation to figures are almost indistinguishable from those of children in the control group. This is observed in both age subgroups;

- latent periods of complex visual-motor reactions (SC 1-3, SC 2-3) among children with auditory sensory deprivation to figures are better than the same indicators in the control group of children;

- significantly worse rates of latent periods of different complexity of reactions to figures are shown by the group of children with visual sensory deprivation. This is explained by the existing problems with the visual analyzer;

- significantly worse rates of latent periods of different responses to sounds are in the group of children with auditory sensory deprivation. This is due to existing hearing aid problems among children with hearing impairments;

- children of the experimental group (with impairment of hearing) have better indicators of sensorimotor response to low-pitched sound stimuli than to high-pitched stimuli;

- significantly better indicators of latent periods of different responses to sounds are shown in the group of children with visual sensory deprivation. This is because the visually impaired have better developed auditory memory, they are quicker to understand and determine the source of the sound;

- based on the analysis of the results of the sensorimotor response study, it can be assumed, that in groups of students with sensory deprivation occurs compensatory-adaptive processes (the process of compensating the lost function of a particular analyzer at the expense of another).

Having analyzed the results of the study of short-term memory and attention it was revealed that:

- indicators of short-term memory for geometric figures of visually impaired students of both age subgroups are higher than in the control group. The best indicator of figurative memory (memory of figures) can be explained by the fact that the formation of the second signal system is fundamentally different; 
- children with visual deprivation of 8-11 years are worse in memorizing the material in contrast to the control group and students with auditory deprivation. This indicates that visually impaired students have low memory that connected with the visual analyzer;

- the presented results give grounds to state that the older the child, the higher the shortterm visual memory;

- the volume of attention among children with visual and hearing impairments was significantly higher than in the control group;

- there is a low rate of information processing among sensory-deprived children of 8-11 years. It can be assumed, that this is due to the abnormality of the central nervous system that can cause deprivation;

- performance, resilience, and shifting indices are better among children in the control group as opposed to students with visual and hearing impairments. In schoolchildren with impaired vision and hearing difficulties there was marked an attention shift, they need more time, leading to the decrease in speed of fulfilling a particular task and increased errors.

In the future, we plan to study the strength and functional mobility of nerve processes, sensorimotor response to a moving object and muscular endurance through the computer system «Diagnost-1M».

\section{References}

[1] Zaiko, M. N., Bits, Y. V., Butenko, H. M. (2008). Pathophysiology. Kyiv: Medicine, 704.

[2] Batuev, A. S. (2010). Physiology of higher nervous activity and sensory systems. Saint Petersburg: Piter, 317.

[3] Makarchuk, M. Yu., Kutsenko, T. V., Kravchenko, V. I., Danylov, S. A. (2011). Psychophysiology. Kyiv: Interservice, 329.

[4] Hasiuk, O. M. (2004). Interrelation of psychophysiological functions with indicators of cardiovascular and respiratory systems in children of junior school age with auditory deprivation. Kyiv, 24.

[5] Kravchenko, Yu. V. (2003). Features of psychophysiological parameters and indicators of hemodynamics in young people with auditory deprivation. Kyiv, 20.

[6] Redka, I. V. (2013). Electroencephalographic features of 8-12-year-old children with visual dysfunctions. Bulletin of problems in biology and medicine, 2 (3), 91-98.

[7] Makarenko, M. V. (1999). Methodology for conducting surveys and evaluating individual neurodynamic properties of higher human nervous activity. Physiological Journal, 4, 125-131.

[8] Makarenko, M. V. (2014). Methodical instructions to the workshop on differential psychophysiology and physiology of higher human nervous activity. Cherkasy: Vertical, 102.

[9] Makarenko, M. V., Lyzozhub, V. S. (2011). Ontogenesis of psychophysiological functions of a person. Cherkasy: Vertical, 256.

[10] Lizohub V. S. (2000). Formation of individual-typological properties of higher nervous activity in ontogenesis. Tavricheskiy mediko-biologicheskiy vestnik, 3 (4), 112-120.

[11] Makarenko, M. V., Lyzozhub, V. S., Pustovalov, V. O., Zghaniaiko, A. V. (2013). Sound of physical health problems with neurodynamic powers of the other central nervous system. Sportyvnyi Visnyk Pridniprov'ya, 2, 20.

[12] Kharchenko, D. M. (2009). Psychosomatic careers: theories, methods of diagnosis, resultsupto. Kyiv: Milenium, 280.

[13] Antomonov, M. Yu. (2006). Mathematical processing and analysis of biomedical data. Kyiv: Malyi Druh, 558.

[14] Zagaykan, J. V., Spryn, A. B. (2018). The effect of sensory deprivation on sensory reaction in children. Cherkasy University Bulletin: Biological Sciences Series, 1, 25-31. doi: https://doi.org/10.31651/2076-5835-2018-1-1-25-31 